\title{
Investigating the Work and Life of Percy Ludgate
}

\author{
Brian Coghlan, Brian Randell, Paul Hockie, Trish Gonzalez, David McQuillan, Reddy O’Regan
}

\begin{abstract}
Percy Edwin Ludgate (1883-1922) is notable as the second person to publish a design for an Analytical Machine, the first after Babbage's "Analytical Engine". We outline the initial results of the first new investigation into the work and life of Percy Ludgate since Randell's papers of nearly 50 years ago and nearly 100 years after Ludgate's death. Firstly we examine the principles of his machine and how it was constructed and worked. Secondly we outline his life. We present a range of new material, including two significant discoveries, one concerning Ludgate's machine, the other his family.
\end{abstract}

Index Terms-Percy Ludgate, Analytical Machine, Irish Logarithms, Multiply-Accumulate (MAC), Division by Convergent Series, Charles Babbage, Analytical Engine

\section{INTRODUCTION}

$P_{t}$ ERCY Edwin Ludgate (1883-1922) is notable as the second person to publish a design for an Analytical Machine [1][2], the first after Babbage's "Analytical Engine" [3]. Strangely enough, he was not a scientist, but a clerk to a corn merchant (and subsequently an accountant), born in Skibbereen and employed in Dublin, Ireland. He was working in his spare time, presumably on his own, from 1903 to 1909, and was not aware of Babbage's work until later. Indeed his engine differed greatly from Babbage's in that it was largely based on multiplication using rods in shuttles plus logarithmic "slides" like a digital evocation of slide rules, while Babbage's was based on addition using cogs and wheels (interestingly, Babbage's initial difference engine efforts were based on sliding rods, although they were not logarithmic [4]). Both Ludgate and Babbage based input on perforated paper (separately for instructions and data), but Ludgate notably unified instruction \& operand sequencing, while Babbage separated them. Either machine would be capable of doing everything a modern computer of their scale could do, although very slowly.

Randell's 1971 and 1982 papers [5][6] revealed Ludgate and resurrected him from obscurity, but nothing new has been published on him since then. Prof. J.G.Byrne collected an original offprint of Ludgate's 1909 paper for what became the John Gabriel Byrne Computer Science Collection [7] in the Department of Computer Science, Trinity College Dublin, and then in 1991 instigated a prize in memory of Ludgate [8]. The Collection now holds copies of all the known literature and records relating to Ludgate and, spurred by the cataloguing of this collection since 2016, the collective authors have undertaken a detailed investigation of his work and life. This and [9] outline the initial results of this first new investigation into the work and life of Ludgate since Randell's papers of nearly 50 years ago and nearly 100 years after Ludgate's death, and provide a range of new material.

Prior to the present investigation there were two central mysteries about Percy Ludgate. One has to do with his machine and the other to do with his life.

Firstly, his 1909 paper explains key principles of his machine, but said it was: "not possible in a short paper ... to go into any detail as to the mechanism ... I must therefore, confine myself to a superficial description, touching only points of particular interest or importance". So machine details are scant. However in 1909 he said he had made: "many drawings of the machine and its parts", and five years later in 1914 he said: "Complete descriptive drawings of the machine exist, as well as a description in manuscript". Clearly he put a lot of work into this. A machine of the complexity that he designed would take many diagrams. Although with a very small probability, somewhere these diagrams might exist. The ultimate objective of the present investigation is to find those drawings and the manuscript, should they still in fact exist.

Secondly, Percy Ludgate died young and single in 1922 aged 39. By 1987 there were no other known descendants of his

\footnotetext{
${ }^{1}$ Date submitted: $27^{\text {th }}$ July 2020.

Brian Coghlan is a retired Senior Lecturer with the School of Computer Science and Statistics, Trinity College Dublin, The University of Dublin, Ireland. He is curator of The John Gabriel Byrne Computer Science Collection. Contact him at <coghlan@cs.tcd.ie>.

Brian Randell is an Emeritus Professor of Computing Science, and Senior Research Investigator, in the School of Computing, Newcastle University, U.K. His book The Origins of Digital Computers: Selected Papers was first published in 1973, by Springer Verlag. Contact him at <Brian.Randell@ ncl.ac.uk>. Paul Hockie is a genealogist from London, U.K.

Trish Gonzalez is a genealogist from Florida, U.S.A. Contact her at <trishalg03@aol.com>.

David McQuillan is a retired systems designer from the U.K. who gives occasional talks on mathematics. Contact him at <dmcq@fano.co.uk>.

Reddy O’Regan is a retired solicitor from Skibbereen, Co.Cork, Ireland. Contact him at <oreganic@live.ie>.
} 
parents. So records are scant too. Randell 1971 [5] said: "an archivist stated that by all normal criteria, it was clear that he had never existed". Yet he did exist, with, it turns out, a sizeable number of relatives and acquaintances, potentially with extant descendants. The second objective of the present investigation was and remains to find any such descendants, and any related documents, photographs and memories that they may have.

\section{II.PERCY LUdGATE’s ANALYTICAL MaCHINE}

\section{II.1. Percy Ludgate's 1909 paper}

Percy Ludgate was the second person in history to publish a design for an analytical machine. His 1909 paper was published in the Scientific Proceedings of the Royal Dublin Society. We have found details in the minutes of the RDS Science Committee [10] that establish the process the paper went through, see Table 1.

\begin{tabular}{|l|l|l|}
\hline Date & Who & Action \\
\hline Prior to 8-Dec-1908 & Percy Ludgate & Submitted his paper. \\
\hline Tuesday 8-Dec-1908 & $\begin{array}{l}\text { RDS Science } \\
\text { Committee }\end{array}$ & "Mr. Percy Ludgate's paper on an Analytical Machine was referred to Prof Conway for a report." \\
\hline Tuesday 12-Jan-1909 & $\begin{array}{l}\text { RDS Science } \\
\text { Committee }\end{array}$ & $\begin{array}{l}\text { "Read Prof Conway's report on Mr Ludgate's paper, it was decided to adopt his suggestion \& } \\
\text { send it to Prof Boys for his report". }\end{array}$ \\
\hline Tuesday 9-Feb-1909 & $\begin{array}{l}\text { RDS Science } \\
\text { Committee }\end{array}$ & $\begin{array}{l}\text { "Mr. C.V. Boys letter on Mr. Ludgate's paper was read \& the paper was accepted for the next } \\
\text { meeting. The Registrar to communicate Prof Boys remarks to the author \& ask him to } \\
\text { emphasize the points which he considers important" }\end{array}$ \\
\hline Tuesday 23-Feb-1909 & $\begin{array}{l}\text { Percy Ludgate } \\
\text { or Prof.Conway }\end{array}$ & $\begin{array}{l}\text { Presented his paper to the next Scientific Meeting (from the published paper, which says: "Read } \\
\text { February 23"). }\end{array}$ \\
\hline Tuesday 8-Mar-1909 & $\begin{array}{l}\text { RDS Science } \\
\text { Committee }\end{array}$ & $\begin{array}{l}\text { "Read Mr. Percy Ludgate's letter in reply to the suggestion made to him in reference to his paper } \\
\text { on a proposed analytical machine." } \\
\text { And: "The three papers read at the last meeting by Mr. Brown, Mr. Moss, \& Mr. Ludgate were } \\
\text { ordered to be printed." }\end{array}$ \\
\hline
\end{tabular}

Table 1 Publication process of Percy Ludgate's 1909 paper

Thus the first reviewer (Prof. Conway) suggested it be sent to Prof. C.V.Boys, presumably for a more expert review. The minutes say "Registrar to communicate Prof Boys remarks to the author \& ask him to emphasize the points which he considers important", and later "Read Mr. Percy Ludgate's letter in reply to the suggestion made to him" (presumably by C.V.Boys). Then Ludgate says at the start of his paper "I desire to record my indebtedness to Professor C.V.Boys FRS for the assistance which I owe to his kindness in entering into correspondence with me".

Ludgate's paper then includes four paragraphs at the start and two paragraphs at the end on Babbage, plus references to Babbage in the middle of the text. The huge difference in how Babbage and Ludgate envisaged their machines suggests he did not know of Babbage's ideas in advance, and that his paper's reviewer Prof. C.V.Boys' suggestions led to him adding the paragraphs on Babbage surrounding the body of his paper, plus the references to Babbage within the body.

No related material has been found amongst Prof. C.V.Boys papers, neither in the London Science Museum nor with his descendants [11]. The paper says at the start "Communicated by Prof. A.W.Conway", and this phrase appears in notices of the presentation on $23^{\text {rd }}$ Feb. 1909 [12], so Conway either communicated the notices or gave the presentation; likely the former as he is not specifically thanked. Despite extensive searches, Prof. Conway's papers and descendants have yet to be found.

\section{II.2. Ludgate's Analytical Machine}

Ludgate's design had four principal parts: the arithmetic unit, storage, input/output and a sequencer for program control, as illustrated in the conjectural sketch in Figure 1. It can be seen that while Babbage used a cylindrical envelope for calculation and a rectangular envelope for storage, Ludgate did somewhat the reverse.

Like Babbage's, Ludgate's machine also had a Mill (a term he used in his 1909 paper), which did addition in the same way. But notably Ludgate introduced a brand new concept, that he called an "Index", to do multiplication based on what are now called Irish Logarithms. The core of his machine did not just do additions; it did multiply-accumulation (MAC), i.e. multiply followed by add to any previous result in the Mill. MAC is important in signal processing, e.g. in radar and astronomy, and more recently in deep AI [13].

The machine could be operated either manually or under program control, the latter using perforated "formula-paper" for code and "number-paper" for data. He also added some cylindrical mechanisms to do division and logarithms (these cylinders were somewhat akin to the pegged cylinders used in musical boxes and automata, but with rows of holes of differing depths, rather than protruding pegs). Again this introduced a new concept, division by convergent series seeded with an estimate from a mechanical equivalent to read-only memory, and executed under the control of a mechanical equivalent of a built-in subroutine. 


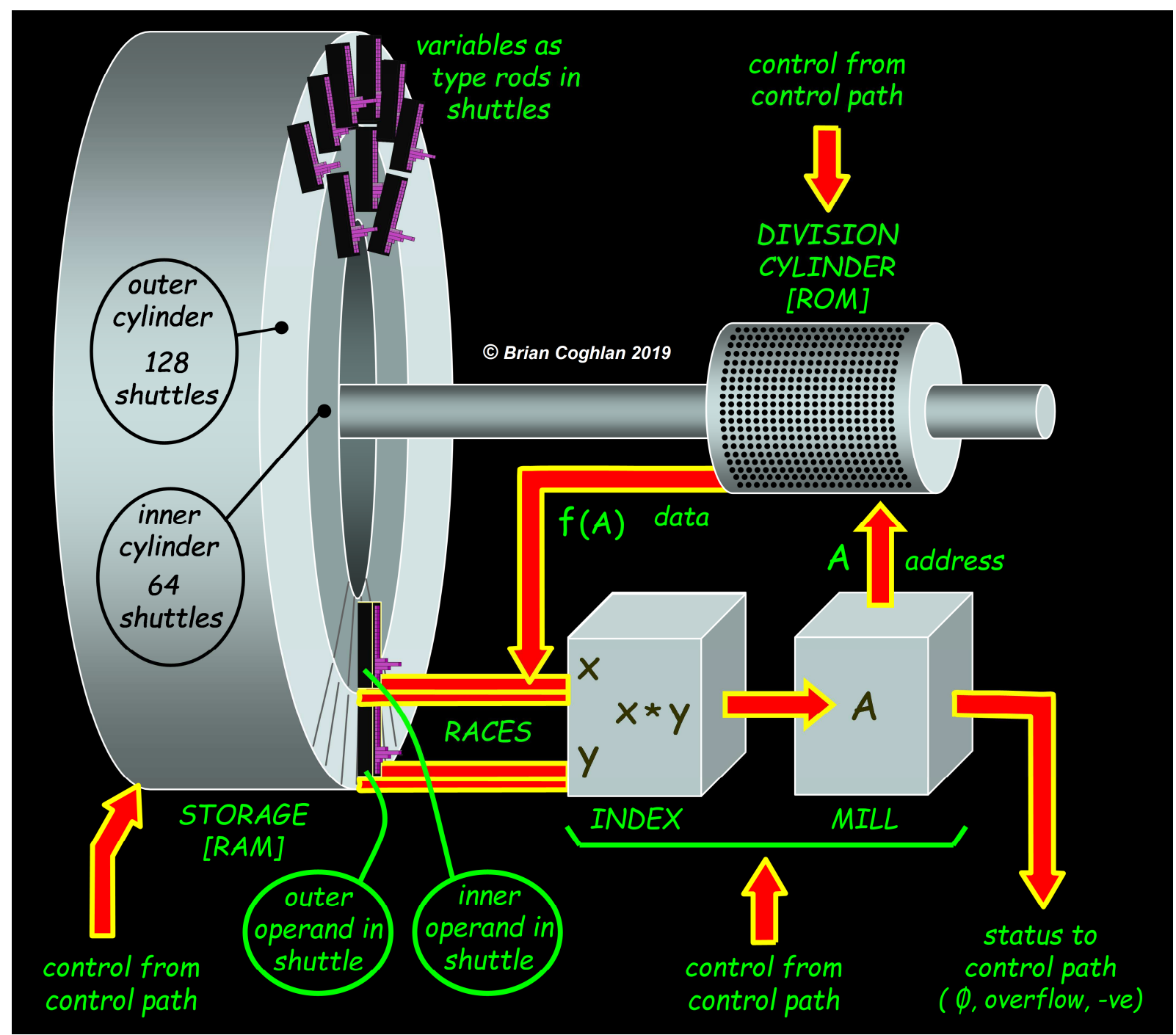

Figure 1 Conjectural sketch of Percy Ludgate's Analytical Machine, where

'control path', 'data path', 'status', 'RAM', 'ROM', ' address', data', are modern terms, all other terms are from Ludgate's 1909 paper Image reproduced courtesy The John Gabriel Byrne Computer Science Collection

A further pièce de résistance was his Storage system, which was based around two concentric cylinders that held numbers in shuttles. Rods protruded from the shuttles. In each shuttle there were 21 rods, one for the sign, and one per digit of a 20 -digit number. The rods protruded from the shuttle between one and ten units, so in principle to represent the value 7 the rod protruded 7 units (but see further below). In order to access a number, the shuttle was rotated to align with the Index. If variable $C$ was in an outer shuttle and variable $D$ was in an inner shuttle, then to perform a calculation $C * D$, each of the storage cylinders was rotated to align those shuttles with the Index. Then the shuttles were brought forward along the "Races" to engage with the Index, and the calculation proceeded with a multiply $C * D$ followed by accumulation of partial product units and tens in the Mill, then the shuttles returned to their cylinders. The result (in the Mill) could then be written to a new shuttle and stored somewhere else in one or both of the two cylinders. This was a very novel form of random access memory, and completely new.

As stated above, the machine's core operation was multiply-accumulate, processed jointly in his Index and Mill. This employed a novel variant of long multiplication that iterated per digit from the most significant digit of the multiplier towards the least significant digit, i.e. in reverse to the traditional order. For each digit of the multiplier, the units of the partial product were generated by the Index and added to the accumulator by the Mill, then the tens of the partial product were generated and added to the accumulator. Figure 2 shows an example, illustrating both the novel iteration order and how the partial products are split into units and tens (but excluding any treatment of Ludgate's carry propagation, which is explored in [9]). 


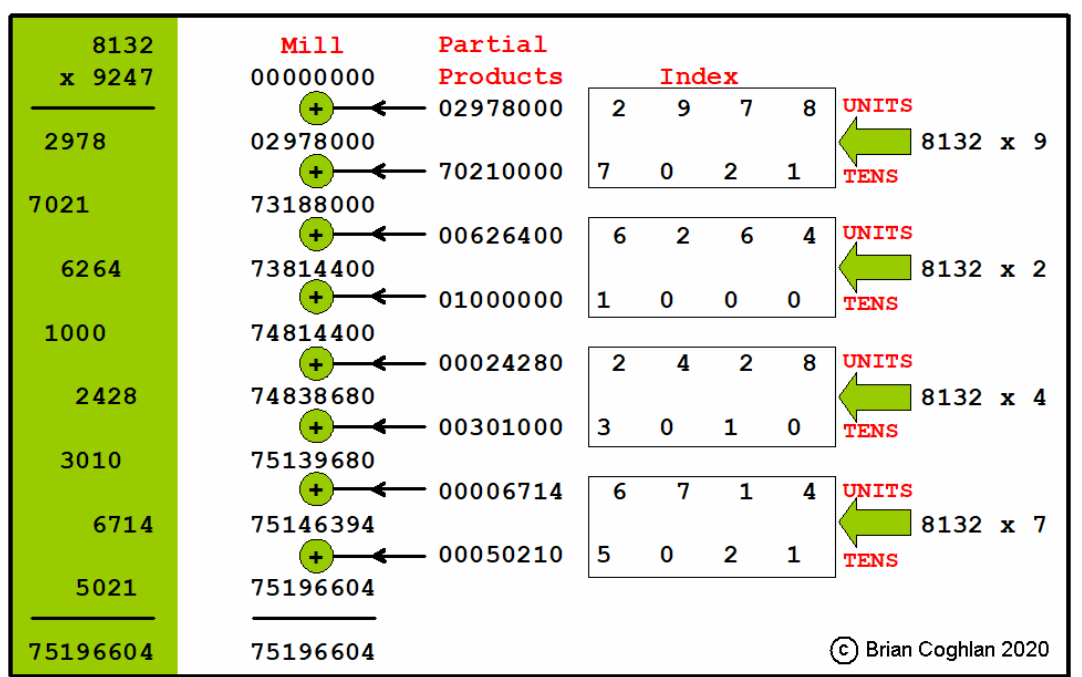

Figure 2 An example of Ludgate's variant of long multiplication, calculating $8132 \times 9247$

Image reproduced courtesy The John Gabriel Byrne Computer Science Collection

Ludgate's Index worked in an analogous fashion to a slide rule, which has scales that are more fine as the numbers increase, such that they obey the logarithmic law that they convert multiplication into additions, i.e. $\log (j * k)=\log (\mathrm{j})+\log (\mathrm{k})$. The $\operatorname{Index}$ embodied a full single-digit multiplication table (for numbers 1-9), as did a few other calculating machines at this time, such as the Millionaire [14]. However the numbers were represented in a logarithmic form, and as lengths, rather than angular positions (of a cogwheel), so that multiplication could be achieved by addition, using simple linear motion. These were not ordinary logarithms, where when real numbers increase the difference between their logarithms continuously reduce. Rather, they were integer values which have been referred to as 'Irish Logarithms'. For two operands $Z_{J}$ and $Z_{K}$, Ludgate's index numbers ensured $Z_{Y}=Z_{J * K}=Z_{J}+Z_{K}$. For example, indexes $Z_{3}=7$ and $Z_{5}=23$, therefore $Z_{15}=Z_{3 * 5}=Z_{3}+Z_{5}=30$. It is not known how Ludgate arrived at his set of logarithms. This matter is discussed in [9], showing a method that we can speculate he might have devised and used. As can be seen in Table 2, simple indexes form a non-monotonic function of the decimal operands, but a monotonic function of the ordinals (because ordinals represent the rank order of simple indexes). Therefore ordinals may be used as a proxy for the decimal operands in circumstances where monotonicity is desirable, and Ludgate employed this. This is explained further below, and outlined in more detail in [9].

\begin{tabular}{|c|c|c|}
\hline $\begin{array}{c}\text { Decimal } \\
\text { operand }\end{array}$ & $\begin{array}{c}\text { Simple } \\
\text { index }\end{array}$ & $\begin{array}{c}\text { Ordinal } \\
\text { number }\end{array}$ \\
\hline 0 & 50 & 9 \\
\hline 1 & 0 & 0 \\
\hline 2 & 1 & 1 \\
\hline 3 & 7 & 4 \\
\hline 4 & 2 & 2 \\
\hline 5 & 23 & 7 \\
\hline 6 & 8 & 5 \\
\hline 7 & 33 & 8 \\
\hline 8 & 3 & 3 \\
\hline 9 & 14 & 6 \\
\hline
\end{tabular}

\begin{tabular}{|c|c|c|c|c|c|}
\hline $\begin{array}{c}\text { Partial } \\
\text { product }\end{array}$ & $\begin{array}{c}\text { Compound } \\
\text { index }\end{array}$ & $\begin{array}{c}\text { Partial } \\
\text { product }\end{array}$ & $\begin{array}{c}\text { Compound } \\
\text { index }\end{array}$ & $\begin{array}{c}\text { Partial } \\
\text { product }\end{array}$ & $\begin{array}{c}\text { Compound } \\
\text { index }\end{array}$ \\
\hline 1 & 0 & 15 & 30 & 36 & 16 \\
\hline 2 & 1 & 16 & 4 & 40 & 26 \\
\hline 3 & 7 & 18 & 15 & 42 & 41 \\
\hline 4 & 2 & 20 & 25 & 45 & 37 \\
\hline 5 & 23 & 21 & 40 & 48 & 11 \\
\hline 6 & 8 & 24 & 10 & 49 & 66 \\
\hline 7 & 33 & 25 & 46 & 54 & 22 \\
\hline 8 & 3 & 27 & 21 & 56 & 36 \\
\hline 9 & 14 & 28 & 35 & 63 & 47 \\
\hline 10 & 24 & 30 & 31 & 64 & 6 \\
\hline 12 & 9 & 32 & 5 & 72 & 17 \\
\hline 14 & 34 & 35 & 56 & 81 & 28 \\
\hline
\end{tabular}

Table 2 Ludgate's simple and compound logarithmic indexes (reproduced from Ludgate's 1909 paper, Tables 1 and 2)

Logarithms and slide rules may seem ancient technology, and indeed go back to Napier c.1614 [15] and Oughtred c.1622 [16]. Slide rules are not commonly used nowadays, but they once were employed widely, especially for scientific and engineering calculations. The advantage of slide rules is their physical simplicity in providing their functionality, compared to other alternatives, even though to many they may now appear a curious oddity. In a similar vein, Ludgate's accumulation worked in an analogous fashion to Napier's "bones", otherwise called "rods", a precursor to slide rules and once widely used across Europe (as an aid to manual calculation) to accumulate partial product units and tens digits that were inscribed on their upper surface.

In summary, Ludgate's machine was entirely mechanical, the main mechanisms seem realizable with the technology of the time, and it was small (from dimensions in Ludgate's paper, about the size of a bar fridge). Ludgate's design was very different to Babbage's. It had a Mill to add like Babbage's (but presumably not influenced by him), an Index to multiply via Irish Logarithms (a new idea), and compact Storage via rods and shuttles (another new idea). Programming and input/output were via punched 
paper in the same vein as Babbage's but quite different (and again in all probability not influenced by him). There is no evidence that Ludgate ever made any attempt to build his machine, and Ludgate's drawings had never been found. We are trying to "reimagine" his design, but it is difficult to say if anything beyond the Storage and Index can ever be built.

\section{ASPECTS OF LUDGATE'S MACHINE}

\section{III.1. Features}

Only a few features are described in Ludgate's 1909 paper. The rest must be deduced by contextual analysis of the paper, largely a process of logical inference or elimination of false propositions, and mechanical or mathematical speculations. They are summarised in Table 3, but explored in [9].

\begin{tabular}{|c|c|}
\hline & Base operation is multiply-accumulate (MAC) not addition \\
\hline & Multiply is done with Irish Logarithms by an INDEX \\
\hline & Long multiply starts at left digit of multiplier \\
\hline \multirow[t]{2}{*}{$¥$} & Numbers must be fixed-point \\
\hline & Multiply-accumulate partial-products are added units first, then tens, by a MILL \\
\hline$¥$ & Timing implies pipelining tens carry adds \\
\hline \multirow[t]{2}{*}{$¥$} & Instruction set: ADD, SUBTRACT, MULTIPLY, DIVIDE, STORE, CONDITIONAL BRANCH \\
\hline & Two-operand addressing for load \\
\hline \multirow[t]{2}{*}{$¥$} & Two-operand addressing for store \\
\hline & Fast for 1909: ADD/SUB $3 \mathrm{sec}, \mathrm{MUL} 10 \mathrm{sec}$, DIV $90 \mathrm{sec}$, LOG $120 \mathrm{sec}$ \\
\hline$¥$ & Storage of 192 variables implies (64 inner +128 outer) shuttles, equispaced \\
\hline \multirow[t]{4}{*}{$¥$} & Hence storage size implies binary storage addressing \\
\hline & Numbers stored via rod for sign \& every digit protruding $1-10$ units \\
\hline & Data input/ output via punched number-paper (or upper keyboard) \\
\hline & Program input/ output via punched formula-paper (or lower keyboard), one instruction per row \\
\hline$¥$ & Manual preemption \\
\hline$¥$ & Measurements in units of an eighth of an inch \\
\hline \multirow[t]{2}{*}{$¥$} & Main shaft gives 'cycle time' of a third of a second \\
\hline & Small size: estimated by Ludgate as $0.5 \mathrm{~m} \mathrm{H} \times 0.7 \mathrm{~m} \mathrm{~L} \times 0.6 \mathrm{~m} \mathrm{~W}$ \\
\hline
\end{tabular}

Table 3 Features of Percy Ludgate's analytical engine

$¥$ denotes inferences that are detailed in [9]

\section{III.2. Unknowns}

Almost everything about its construction is unknown. For a small sample of these unknowns, see Table 4. Many such issues are explored in considerable detail in [9].

\begin{tabular}{|l|l|}
\hline How shuttles were selected in storage cylinders & Any internal dimensions \\
\hline How a shuttle was moved & Any internal timing \\
\hline How the INDEX mechanism worked & Almost everything about program control \\
\hline How the MILL mechanism worked & Almost everything about input \& output \\
\hline
\end{tabular}

Table 4 Sample of known unknowns of Percy Ludgate's analytical engine

\section{III.3. Reducing the Unknowns: New Discoveries}

Clearly the discovery of drawings by Ludgate would reduce the unknowns, so this has been an ultimate target of the research, but any discovery of new information about Ludgate's design would help. And in fact, prompted by our open call for information about Ludgate, just before Christmas 2019, Ralf Beulow of Heinz Nixdorf MuseumsForum with Eric Hutton [17] discovered a pair of articles about Ludgate's machine in the 1909 issues of the popular science magazine "The English Mechanic and World of Science" [18]. One was a very brief summary [19] of Ludgate's 1909 paper, with no new information.

The other article [20] did indeed promise new information, if validated, and included the first known diagram of Ludgate's machine! This article was attributed to "Engineering". A search by Jade Ward of University of Leeds Library discovered the 
article was in fact an abbreviated extract of an article [21] published a month earlier, i.e. just over three months after Ludgate's original Royal Dublin Society paper, in "Engineering" (a London-based monthly magazine founded in 1865). This article, which from here onwards will be referred to as "Engineering [21]", is reproduced in full as Appendix I.

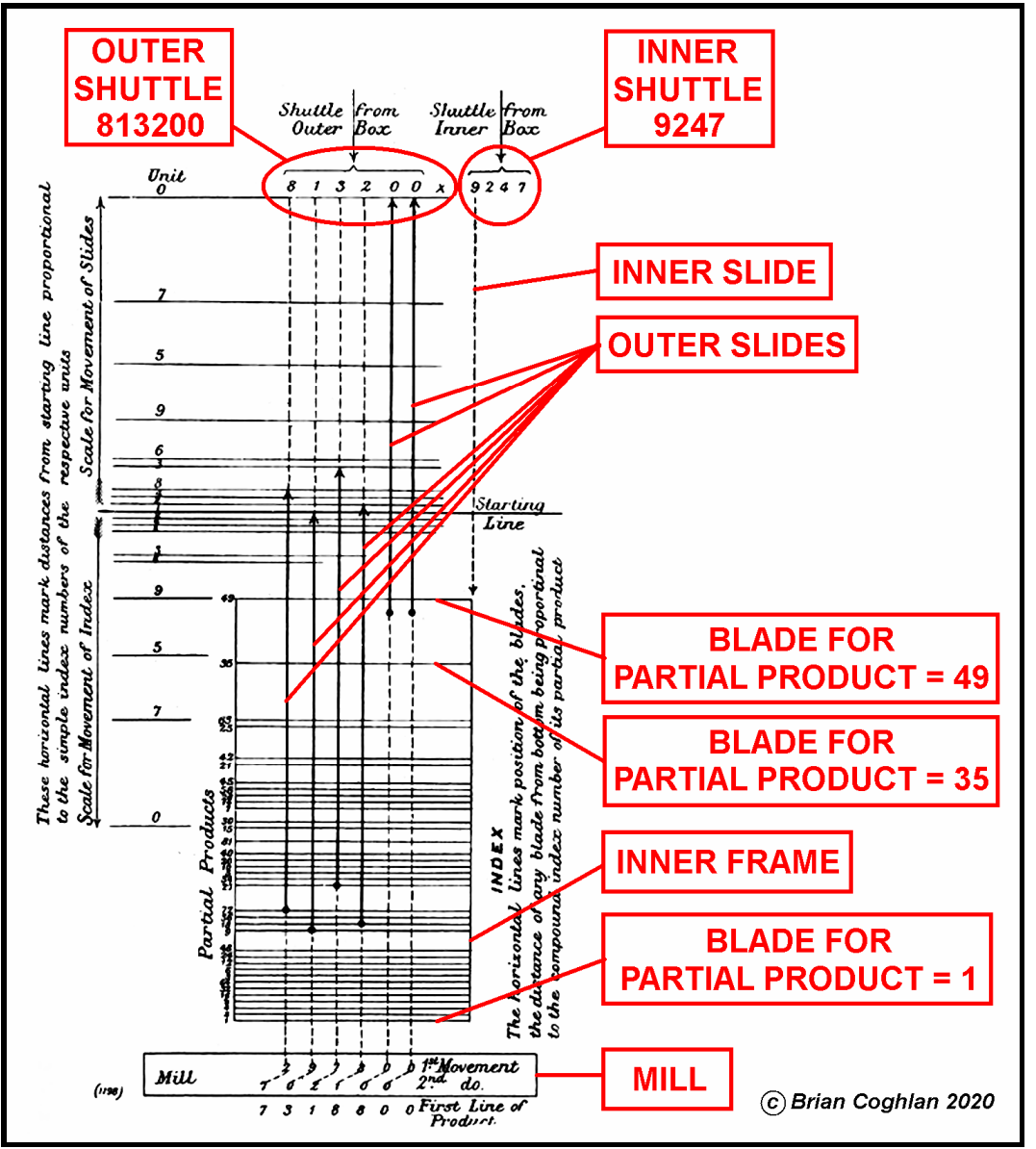

Figure 3 Annotated version of the diagram from Engineering, 20 th Aug. 1909, Pages 256-257 [21]

See Appendix I for the original full-size image. Image reproduced courtesy The John Gabriel Byrne Computer Science Collection

Figure 3 shows an annotated version of the diagram from Engineering [21] (an identical copy of which appeared in "The English Mechanic and the World of Science" [20]), which presumably was provided, and perhaps actually drawn, by Ludgate.

The text of the article of Engineering [21] at first appeared to us to contradict Ludgate's 1909 paper, but as analysis has progressed it has begun to seem more likely that the text was provided by Ludgate too (the article includes a detailed explanation of the diagram). Ludgate and the writer of the article are quite precise in what they say. In fact treating Ludgate's paper and the article as equally valid has uncovered ways the design may have been that would have been very hard to arrive at with only Ludgate's 1909 paper.

For example, we have deduced the following essential principles of operation. Ludgate employed logarithmic index "slides" to implement his Irish Logarithms. Figure 4 (based on [22]) shows a slide with annotations for the decimal, ordinal and index numbers. For each ordinal value on the slide axis $Y$, there was a corresponding simple index value on the slide axis $X$. It can be seen that the sequence of the simple index values forms a monotonic logarithmic profile along the $X$ axis. It also shows a storage shuttle with a type rod representing the decimal value of ' 8 ' (represented by the ordinal value ' 3 '). The principle of operation is that the slide moves up until it hits the rod. When it does so, it will have been displaced by a simple index of 3 units. By contrast for a shuttle with a type rod representing the decimal value of ' 0 ' (represented by the ordinal value ' 9 '), the slide will be displaced by a simple index of 50 units. It is thought quite likely that ordinals were used in the storage shuttles as a proxy for the decimal operands in order that the series of slide profile changes in $Y$ would be monotonic, as this would facilitate the progressive movement of the slides along the $X$ axis for all possible decimal values.

The slide and shuttle $Y$-axis of Figure 4 will actually be edge-on, facing directly away from the viewer (reducing their visibility to lines as in Figure 3), but they are illustrated as shown to aid understanding. The outer and inner slides faced each other on a common 'starting line' aligned with their simple index ' 0 '. To multiply, the slides were moved towards their respective shuttles. Figure 5 shows, for example, the leftmost slide when moved until it hits the outer shuttle left type rod representing decimal value ' 8 ', and therefore displaced by simple index $Z_{8}=3$. Figure 5 also shows the inner slide when moved until it hits the inner shuttle 
type rod representing decimal value ' 9 ', and therefore displaced by simple index $Z_{9}=14$. Like a slide rule, the relative displacement of the two slides is then the compound index $Z_{72}=Z_{8^{*} 9}=Z_{8}+Z_{9}=3+14=17$, representing the decimal partial product $8 * 9=72$. Thus the logarithm of the product of two digits is represented by the increase in overlap of the two slides in $X$ after they have been displaced from their starting alignment.

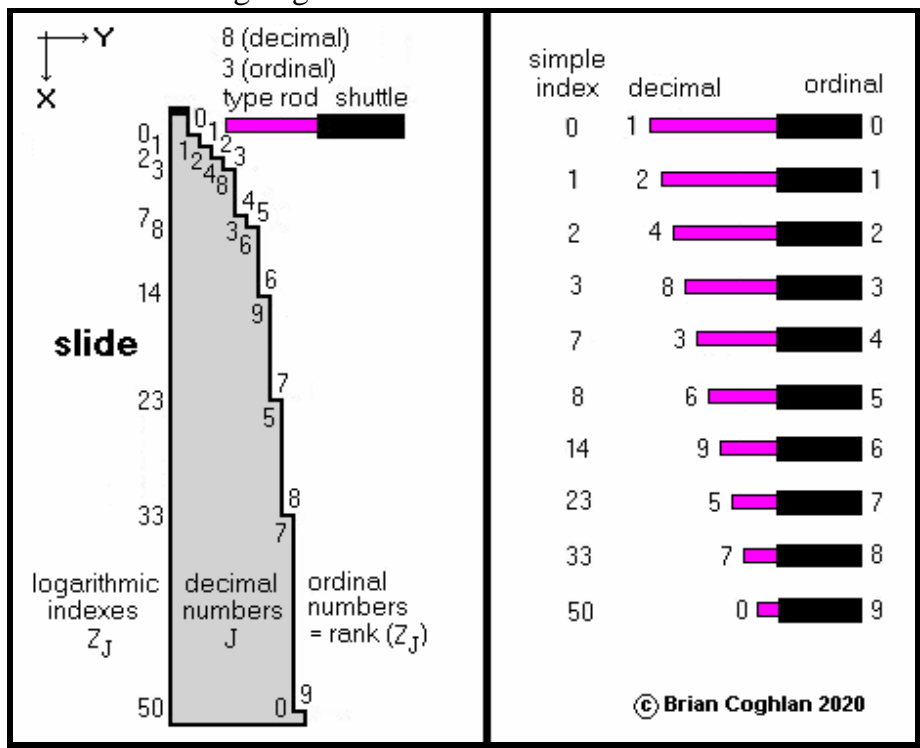

Figure 4 (left) Ludgate's logarithmic slide, (right) shuttle rod extensions for simple indexes, decimal and ordinal values Image reproduced courtesy The John Gabriel Byrne Computer Science Collection

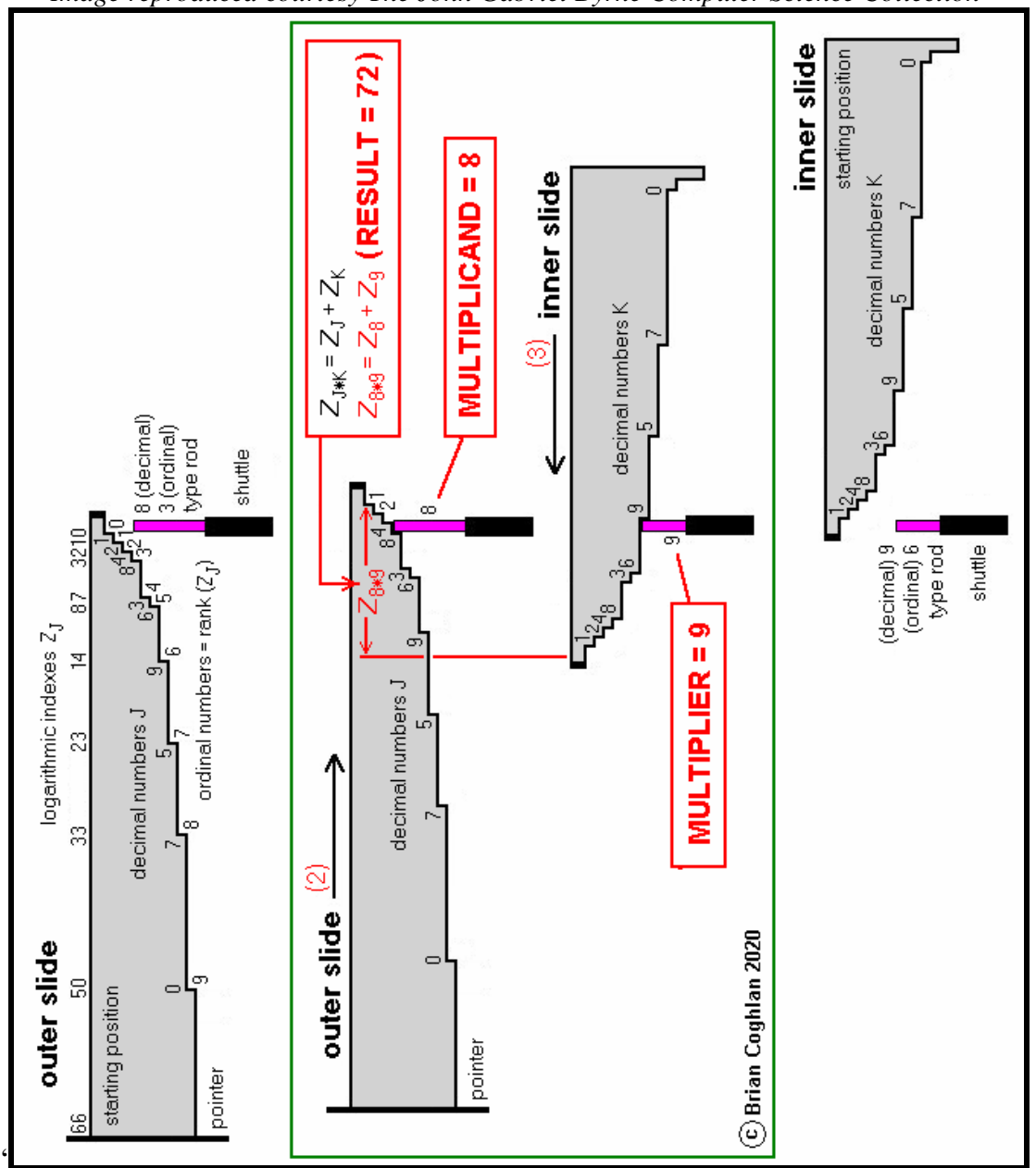

Figure 5 Multiplication using Ludgate's logarithmic slides for multiplication of $8 * 9=72$ Image reproduced courtesy The John Gabriel Byrne Computer Science Collection 
The upper part of Figure 6 shows a 6-digit outer shuttle and a 4-digit inner shuttle, representing a machine with a 6-digit outer operand (the multiplicand 813200) and a 4-digit inner operand (the multiplier 9247) as per Engineering [21]. These correspond to the variable values to be multiplied, which are from the outer and inner storage cylinders, respectively. These inner and outer shuttles were in line as shown. Figure 6 also shows six outer slides and one inner slide. The two types of slide are likely to have had the same logarithmic profile, as is shown. Each of the outer slides was moved to hit a corresponding digit of the outer shuttle. Then starting with the most significant digit, the inner slide moved one digit at a time to hit the less significant inner shuttle digits, while the Mill accumulated the succeeding partial products to produce the result of Ludgate's variant of long multiplication. Figure 6 shows the partial products '72', '9', 27, '18', 0', 0' for the six outer slides. This figure reproduces the example multiplication of the outer operand (813200, the multiplicand) by the most significant digit (9) of the inner operand (9247, the multiplier) of Engineering [21] as per Figure 3. Ludgate's 1909 paper includes an almost identical example.

Ludgate's index was more than just the slides and shuttles, and in fact was a quite complex multiplicity of moving parts. Much of this related to converting the relative displacement $Z_{\mathrm{J} * \mathrm{~K}}$ to discrete increments or decrements of a result held on the set of "figure wheels" that Ludgate called the Mill, in which digits were represented by the rotational positions of the wheels. The two slide types existed within different physical structures. There were twenty of the outer slides (with the pointer attached at one end) in an outer frame but free to move within it (so for illustrative purposes that frame can be treated as invisible). In contrast there was just one inner slide, firmly attached to an inner frame containing multiple blades. There was one blade per compound index, i.e. one per uniquely valid partial product, as per Engineering [21], see Figure 6. The relative position of the pointer over the blades indicated the partial product. The way in which the blades were composed and utilized was a very clever arrangement.

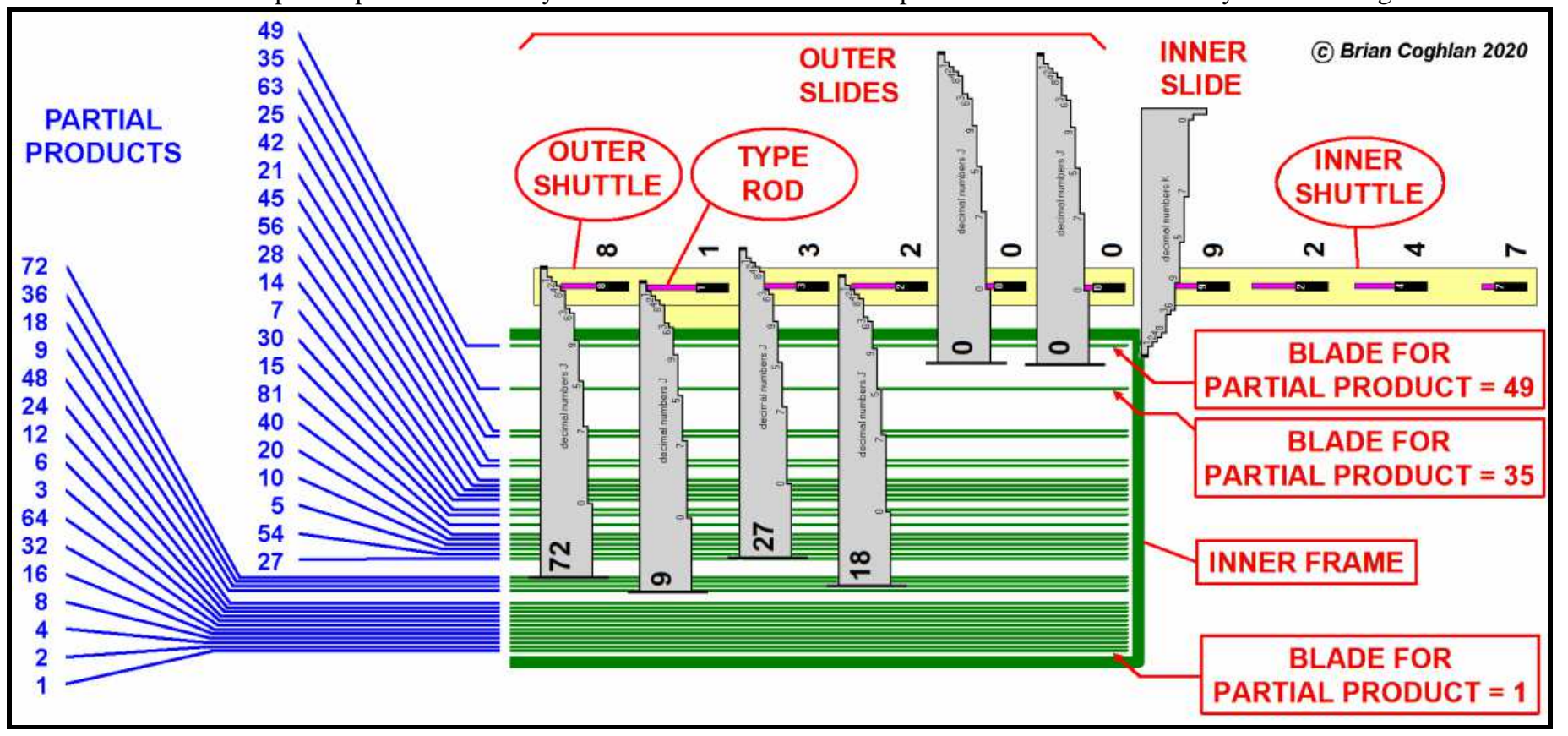

Figure 6 Ludgate's outer and inner logarithmic index slides, and inner frame with blades for compound indexes.

Image reproduced courtesy The John Gabriel Byrne Computer Science Collection

It is clear from Ludgate 1909 that the 20-digit multiply-accumulate procedure was as follows:

(1) The outer (multiplicand $\boldsymbol{b}$ ) and inner (multiplier $\boldsymbol{a}$ ) operand shuttles are moved to the starting line "near the Index", with the inner slide aligned with the most-significant rod of the inner shuttle (the left rod).

(2) The set of 20 outer slides move in one direction until they hit the rods of the shuttle holding the value of the outer operand. The slides convert the digits to "simple index numbers", essentially the logarithmic indexes of the digits of that operand.

(3) Then the single inner slide is moved in the opposite direction until it hits the rod of the shuttle that it is aligned with; the rod holds the value of that digit of the inner operand. The inner slide converts that digit to a simple index number, i.e. the logarithmic index of the value of that digit of that operand.

(4) "as the index is attached to the last-mentioned slide, and partakes of its motion, the relative displacement of the index and each of the [outer operand] slides ... [and] pointers attached to the [outer operand] slides, which normally point to zero on the index, will now point respectively ..." to the compound index number, essentially the sum of the simple index numbers, representing multiplication of the operands.

(5) Next all the compound index numbers are mapped by "movable blades" to numerical units and tens of the partial products and "conveyed by the pointer to" the Mill and accumulated in the Mill.

(6) Then the Index and its attached inner slide performs a "rapid reciprocating action" to align with the rod of the inner shuttle 
that holds the value of the next less significant digit of the inner operand.

(7) Operations (3-6) are repeated for each of the rods of the inner shuttle "until the whole product of $\boldsymbol{a b}$ is found".

(8) Then "The shuttles are afterwards replaced in the shuttle boxes".

These repetitions of operations for each of the rods of the inner operand digits until the whole product is found can be observed in the cut-down 6-digit by 4-digit example in Figure 7. Comparison of the quadrants of Figure 7 very clearly shows how the outer slides do not move as the iterations of operations (3-6) above proceed. Only the inner slide and its frame move together in two dimensions (vertically up to retract, then horizontally right to the next digit, then vertically down to hit that digit's type rod) as they perform each "rapid reciprocating action" of operation (6) above to move digit-by-digit from the most to least significant digit of the inner operand.

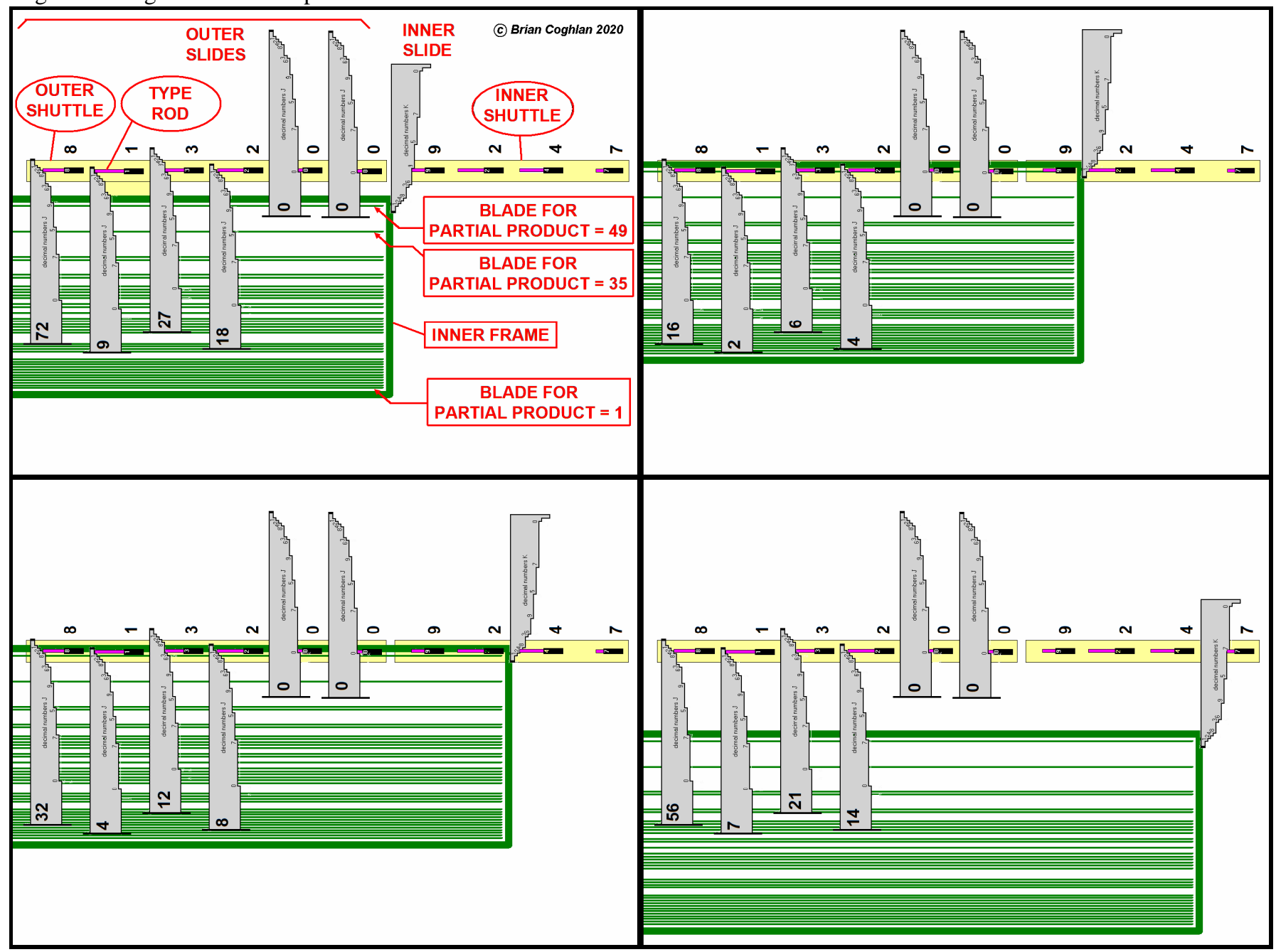

Figure 7 Ludgate's procedure for multiplication of two operands,

representing a machine with a 6-digit outer operand and a 4-digit inner operand as per Engineering [21]

Top Left: iteration 1, multiplicand '813200' multiplied by multiplier digit '9' (from Figure 6)

Top Right: iteration 2, multiplicand '813200' multiplied by multiplier digit ' 2 '

Bottom Left: $\quad$ iteration 3, multiplicand '813200' multiplied by multiplier digit ' 4 '

Bottom Right: $\quad$ iteration 4, multiplicand ' 813200 ' multiplied by multiplier digit ' 7 '

Between each quadramt of the figure the Index and its attached inner slide moves to the next multiplier digit Note that the slides and shuttles will actually face directly away from the viewer, but are shown as is to aid understanding Image reproduced courtesy The John Gabriel Byrne Computer Science Collection

Few details are available of how the partial products were accumulated. It is not possible in this short paper to go into the detail, but all this is considered in the (rather dense) analysis in [9]. A surprising amount of understanding has emerged, conjectural construction detail has been uncovered, some useful dimensional, geometric and timing inequalities established, and an effort has been made to codify these new facts. Work has begun on both simulating parts of the machine and "re-imagining" it with modern engineering software. Figure 8 shows early 3D renditions of the possible re-imagined Ludgate races, shuttles and Index performing the first iteration of the same multiplication as shown in Figure 7, i.e. positioned as shown in Figure 6 and in the top-left quadrant of Figure 7. 


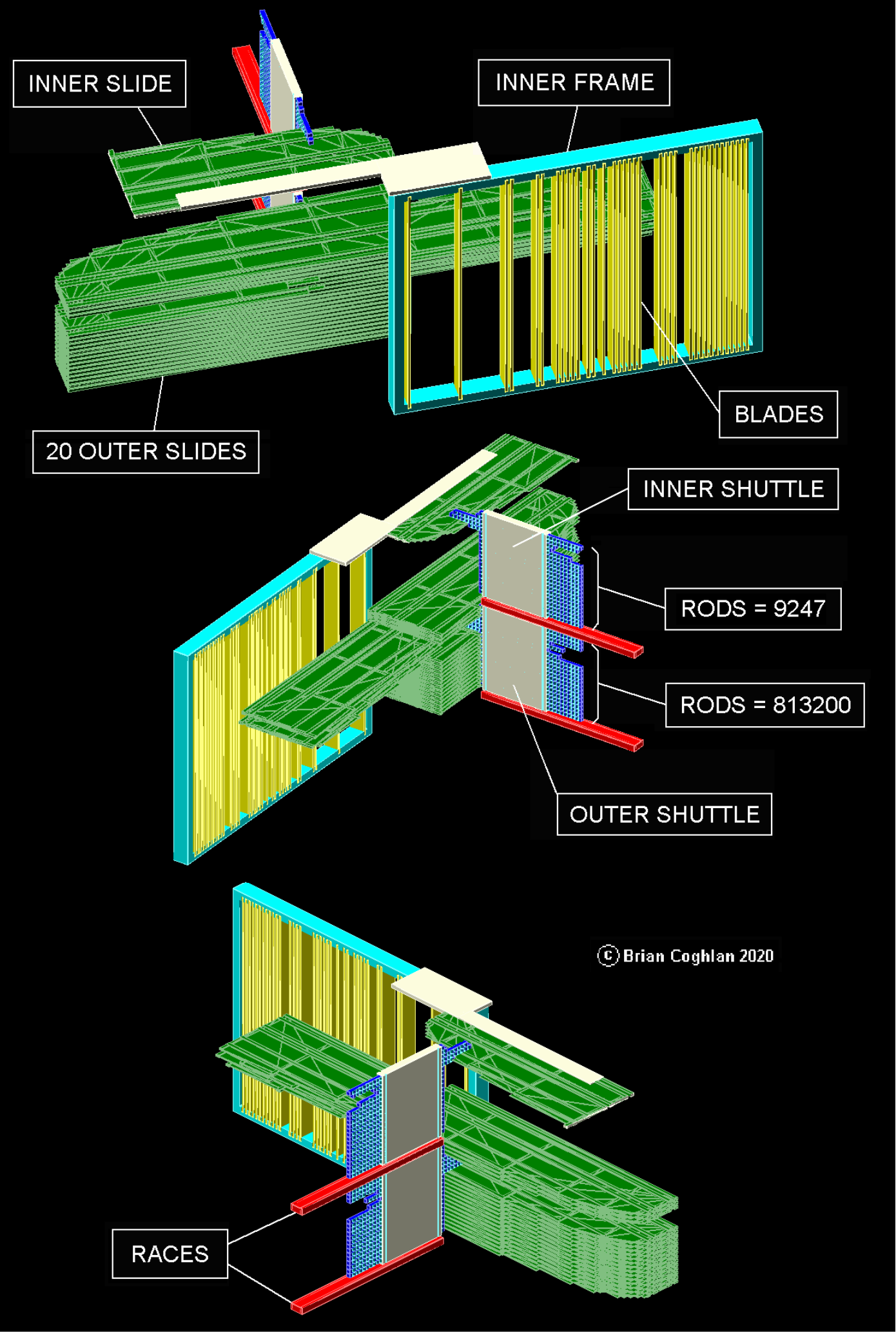

Figure 8 Early 3D rendition of Ludgate's races, shuttles and Index for multiplication of two 20-digit operands, performing the first iteration of the same multiplication as shown in Figure 7,

with multiplicand '813200' multiplied by multiplier '9247' as per Engineering [21]

(the sign rod is at the top of each shuttle, next to the least-significant digit's type rod).

From top to bottom: front, left-rear and right-rear three-quarter views

Image reproduced courtesy The John Gabriel Byrne Computer Science Collection 


\section{LUDGATE’S LIFE}

In order to preserve this account's chronological flow the material below includes previously known facts from Randell, in each case clearly cited, e.g. as (Randell 1971 [5]). Otherwise the material below has all been discovered by the present investigation. Further extensive details of his ancestry collected by Brian Coghlan, Paul Hockie and Trisha Gonzalez since 2016 are preserved for this account in our Collection [7] and online as [23][24][25][26][27][28], while updated material is aggregated in [8]. These may be referred to for details of all births, marriages and deaths and other genealogical facts given in this paper, and much else. During the present investigation archival records have been aggregated from a variety of official sources. Copies of these records are preserved in our Collection and also listed in [28], but permission will be required from those sources before these records can be made "open access", if ever.

\section{IV.1. Childhood}

Percy Ludgate was born on 2nd Aug. 1883 in Townshend Street, Skibbereen (see Figure 9). We have traced the Ludgates back to his great-great-grandfather Matthew Ludgate, who lived at Marble Hill in the early 1700s [25]. His great-grandfather John Ludgate and grandfather Robert Ludgate farmed nearby [29]. His father was an ex-soldier, Michael Edward Ludgate, from Kilshannig, Mallow, Co.Cork. His mother Mary Ann Ludgate née McMahon, was born in Iden, Sussex, of an Anglo-Irish military family [25][28]. After Michael retired to Skibbereen in Co.Cork in 1876 [25] he in 1882 advertised as a shorthand tutor [30]. Percy was born in Skibbereen in 1883, the eighth and youngest child. From 1883 on there is a gap of 7 years during which the family's whereabouts are as yet unknown.

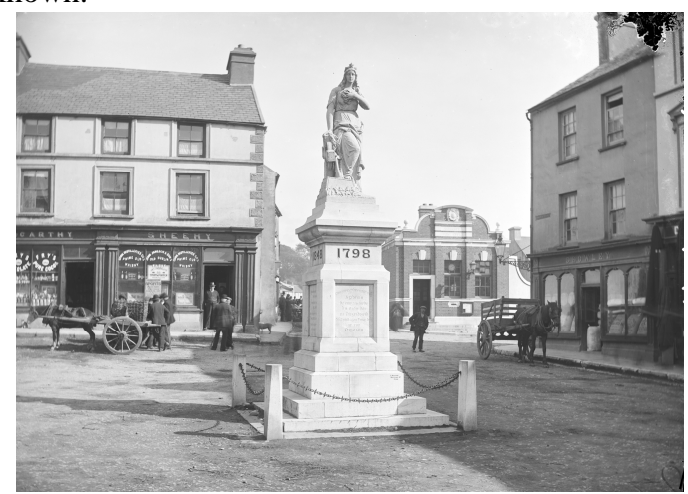

Figure 91798 Memorial, Skibbereen, Percy Ludgate's birthplace Image reproduced courtesy of The Southern Star

From 1890-1898 Percy Ludgate's family then appear in Thom's Directory at 28 Foster Terrace, Dublin, as teachers of shorthand [31]. Clearly this had become a small-scale family business. It was thought that 28 Foster Terrace no longer existed, but recently Gerry Kelly has discovered that the terrace was renumbered in the 20th Century, and that No.28 is thought to have become No. 46 [32], which does still exist, see Figure 10.

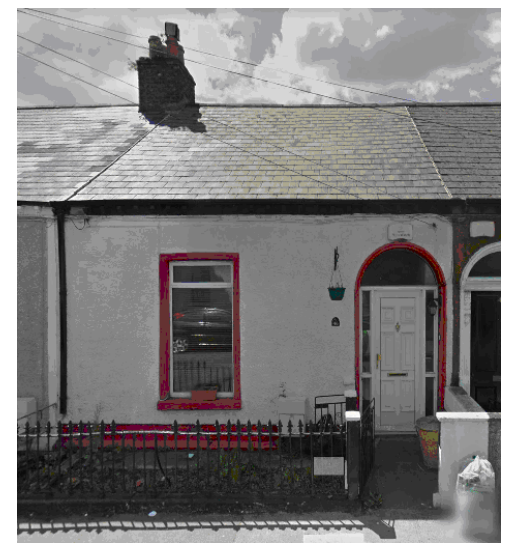

Figure 1046 Foster Terrace, Ballybough, Dublin, Percy Ludgate's first home in Dublin Image reproduced courtesy Gerry Kelly

From school records it is known that during 1890-91 Percy attended St.George's Infants School (aged 7-8) [24]p.80. From 1892-95 he is said to have attended St.George's National School (aged 8-12) (Randell 1971 [5]), but there were two such schools in north Dublin, one behind St.George's Church in Temple Street, the other in North Strand, and for this period neither school's records have yet been found. His father was Episcopalian (a branch of Anglican Church) [33], and Percy attended St.George's Church (Randell 1971 [5]). 


\section{IV.2.Adolescence}

From 1896-98 Percy must have attended (an as yet unknown) secondary school, as it was compulsory until age 14 [34], and given his subsequent history must surely have excelled there.

In 1898 the London Gazette published that Percy Ludgate (then aged 15) was appointed a "Boy Copyist" in the Irish Civil Service [35]; this was a temporary post for boys aged 15-20 years. In 1899 (aged 16) his family moved to 30 Dargle Rd, Drumcondra, two miles northward [36], see Figure 11, whilst his father Michael (giving an address in Balbriggan) was imprisoned in Kilmainham Gaol for non-payment of debt [25]. In 1900 (when Percy was aged 17) his brother Frederick married Alice Walshe [26][28].

In 1901 (aged 18) the Irish Census lists Percy, his mother and a brother Alfred at 30 Dargle Rd. Percy is listed as a Civil Servant (Boy Copyist) in the National Education Office [33]. Frederick and Alice are listed at 24 Dargle Rd (just six doors away), and father Michael in Balbriggan (17 miles away). His other brother Thomas and wife Bedelia are listed in Cork.

In Mar. 1903 Percy was the top Irish candidate in the Civil Service exams for Assistant Clerks [37]. Clearly he must have excelled at Classics and Maths at school. He passed the medical, but for unknown reasons was not appointed to a position, while others with lesser results were [35]. In Aug. 1903 on his $20^{\text {th }}$ birthday Percy's Boy Copyist post expired, marking the end of his Civil Service career [38]. His daily occupation from 1903 is not yet known.

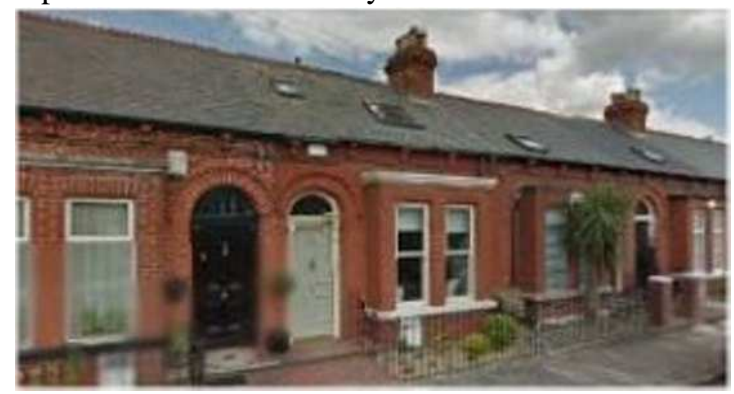

Figure 1130 Dargle Road, Drumcondra, Percy Ludgate's second home in Dublin Image reproduced courtesy The John Gabriel Byrne Computer Science Collection

In that year he must have started work on his Analytical Machine, as his 1909 paper (which was submitted in Dec. 1908) states it was the result of "six years' work". It is not obvious why he became interested in automating complicated mathematical calculations, whatever his exposure to standard calculating machines. Nor have we discovered obvious motivations or influences during our extensive ancestral searches. At this time very few calculating machines were based on multiplication, one exception being the Millionaire calculator [14], and only Thomas Fowler's ternary calculator c.1840 [39] used rods or plates (as did Konrad Zuse's Z1 c.1937 [40]). His niece said it was a private hobby, on which he did "work nightly, until small hours of the morning" (Randell 1971 [5]). There remains the question of what he did in daylight hours.

\section{IV.3.Adulthood}

In Oct. 1904 (aged 21) Ludgate passed the Civil Service exams for Clerkships $2^{\text {nd }}$ Division of the Civil Service (having passed $1^{\text {st }}$ Division a year earlier), but failed the medical [35]. In Feb. 1905 (aged 22) the "Case of Mr. Percy Ludgate - Irish Civil Service" was raised in the House of Commons, Westminster, by Timothy Harrington MP KC (who owned the United Ireland and Kerry Sentinel newspapers). The petition was for a new medical examination with a view to being certified for one or other of the positions for which he had passed exams. He got a negative response from the Financial Secretary of the Treasury (soon to be Duke of Devonshire): “As nearly a year had elapsed since Mr. Ludgate's medical examination for an assistant clerkship, it was necessary to re-examine him before issuing him a certificate for a second-division clerkship. The result of the medical examination proving unsatisfactory the Civil Service Commissioners were unable to grant a certificate for either position" [41].

By the 1911 Census, Percy, his mother and Alfred were still at 30 Dargle Rd. Percy was listed as a commercial clerk to a corn merchant [42], but it is not known when this began. It is possible it was a deliberate first step towards an accounting career.

In Dec. 1908 (aged 25) he submitted his paper to the Royal Dublin Society, and in Apr. 1909 "On a Proposed Analytical Machine" was published in their Scientific Proceedings [1]. In July 1909 a review by Prof. C.V.Boys of the paper was published in Nature [2]. Percy Ludgate's publication was a stunning achievement for a clerk to a corn merchant, to whom the RDS Science Committee, including several Fellows of the Royal Society and numerous professors, could well have been daunting. He and his proposed machine would have become known in what he may have thought an exalted circle.

In 1914 (aged 31) his paper "Automatic Calculating Machines" [43] was published in the Handbook of the Napier Tercentenary Exhibition, which took place in Edinburgh during 24-27th July (World War I started on the 28th July). This paper focussed on Babbage, but mentioned Ludgate's 1909 design, and a subsequent difference engine design [44]. That Ludgate, rather than a notable mathematics professor, should describe Babbage's engines is curious.

During World War I (aged 31-35) he was engaged by a War Office committee (led by T.Condren-Flinn, of Kevans \& Son 
accountants) on the production and sale of oats for cavalry, which involved planning and organisation on a vast scale, and Ludgate was apparently praised for his contribution (Randell 1971 [5]).

Another curiousity is that after the 1909 and 1914 papers there was very little mention of his work. Given C.V.Boys' 1909 report in Nature, and the c.1910 promotion by Henry Babbage of his father's machine, one might expect that the Encyclopedia Britannica would have mentioned those ideas, but the 1911 edition does not [45]. Maybe World War I upset the dissemination of Ludgate's ideas. Certainly they had become relatively unknown by the time of Baxendall's well-known 1926 Science Museum catalogue Calculating Machines and Instruments [46], his mention in which stimulated Randell's 1971 investigation.

\section{IV.4.Maturity}

It is commonly implied in relation to his 1909 paper that he was then an accountant, but that was not so until eight years later. For a period of at least two years [47], Ludgate studied accountancy at the Rathmines College of Commerce (subsumed into the Dublin Institute of Technology in 1992 [48]), then in 1917 (aged 34) he got a gold medal in Accountancy [49]. It is not known when he started working at Kevans \& Son, 31 Dame Street (ultimately subsumed into Price Waterhouse Cooper, now known as PWC [50]), see Figure 12. On any of his likely regular routes from home to work he could not have avoided seeing the impact of the Easter uprising of 1916 and the general mess created, much of which remained for years. Similarly, he could not have avoided witnessing the 1918-19 Spanish Flu epidemic, the War of Independence (1919-1921), or the start of the Civil War in June 1922.

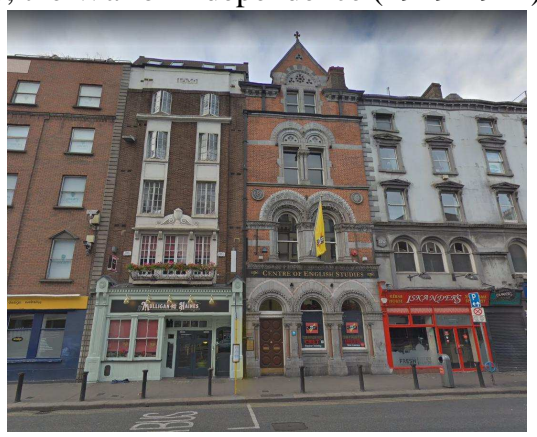

Figure 1231 Dame Street, Dublin, the location of Kevans \& Son, where Percy Ludgate worked as an accountant Image reproduced courtesy The John Gabriel Byrne Computer Science Collection

He remained with Kevans \& Son until 1922 as an accountant; a colleague stated he "possessed characteristics one usually associates with genius, ... he was so regarded by his colleagues on the staff ... humble, courteous, patient and popular". His niece Violet, daughter of Frederick and Alice, stated that "Percy ... took long solitary walks ... gentle, modest simple man", she "... never heard him make a condemning remark about anyone", she thought him "... a really good man, highly thought of by anyone who knew him", and that he "... Always appeared to be thinking deeply” (Randell 1971 [5]). The only known photograph of him, provided by Violet to Randell, is shown in Figure 13, probably taken in the last five years of his life.

He never married, which is a pity as if he had we would probably have been able to find out more about his life.

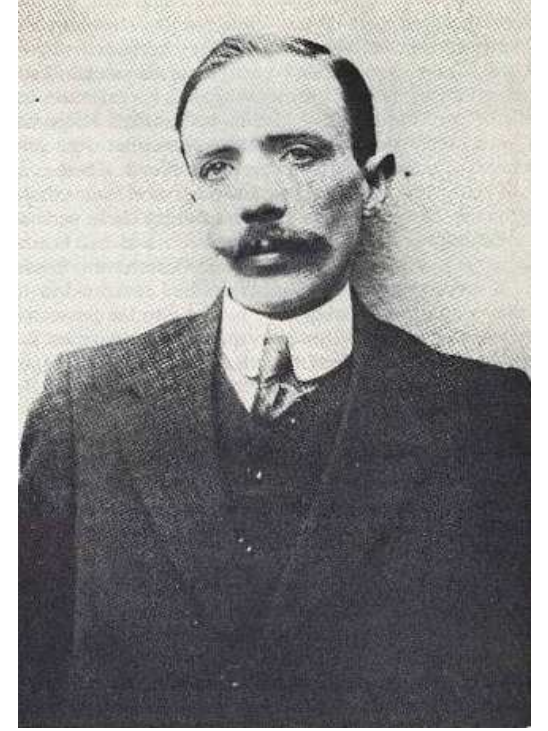

Figure 13 Percy Ludgate, image reproduced courtesy Brian Randell 


\section{IV.5.Tragic end}

In Dec. 1921 Ludgate's brother Frederick died of tuberculosis [26][28]. In Oct. 1922 Ludgate developed pneumonia after a holiday in Lucerne, and on the $16^{\text {th }}$ Oct. 1922 Percy Edwin Ludgate died aged 39, quickly followed on the $22^{\text {nd }}$ Oct. 1922 by the death of Frederick's wife Alice, she previously having nursed Percy (Randell 1971 [5]).

In the UK and Ireland, life expectancy was 57 years in 1922 [51], and his family died at an average age of 58 years, so Percy died younger than expected. That Alice died six days later suggests a highly infectious illness. His death certificate states cause of death as catarrhal pneumonia (now bronchopneumonia), which mostly accompanies diseases like influenza [52]. The 1917-20 Spanish Flu pandemic had a minor peak in 1922, e.g. in Bern in Jan. 1922 [53], so it is possible Percy and then Alice contracted it.

\section{IV.6. Last resting place}

Michael Ludgate died in 1923 in Belfast [25]. Percy's mother Mary died aged 96 in 1936. His remaining siblings Thomas died in 1951, Alfred in 1953, and Augusta in 1954, so by 1954 he, his parents and siblings had all died [25][28]. Those who had been living in Dublin were all buried in the same grave in Mount Jerome Cemetery [54][24]p.95-99. His only living close relative, Violet, died in 1987. Percy's home from 1899 until his death in 1922, where he did his famous work, still exists in good condition [24]p.27-29, 108. On the other hand the Ludgate grave, occupied by Frederick, Percy, Alice, Mary and Alfred, and owned by Alfred [55], who made no Will, lay unmarked and in poor condition in 2018, and could only be marked with permission from the owner, who was dead, or by close descendants, but there were no known descendants [54]. This was a very unsatisfactory situation given Percy Ludgate's importance to the history of computer science.

But then, astonishingly, we found a descendant of Violet! Subsequently the following details emerged. In 1935 Violet gave birth to a daughter, who in 1936 was privately adopted and renamed, and was brought up overseas, married. gave birth to and raised 6 children. The children, who are direct descendants of three occupants of the Ludgate grave, were in 2019 allowed to erect a grave marker, see Figure 14. Thus his ancestry [25][26][27], which continues to be investigated as one possible path to finding preserved family material relating to Ludgate's life and work, has in fact first impacted progress on the previously intractable legal issue of marking the Ludgate grave.

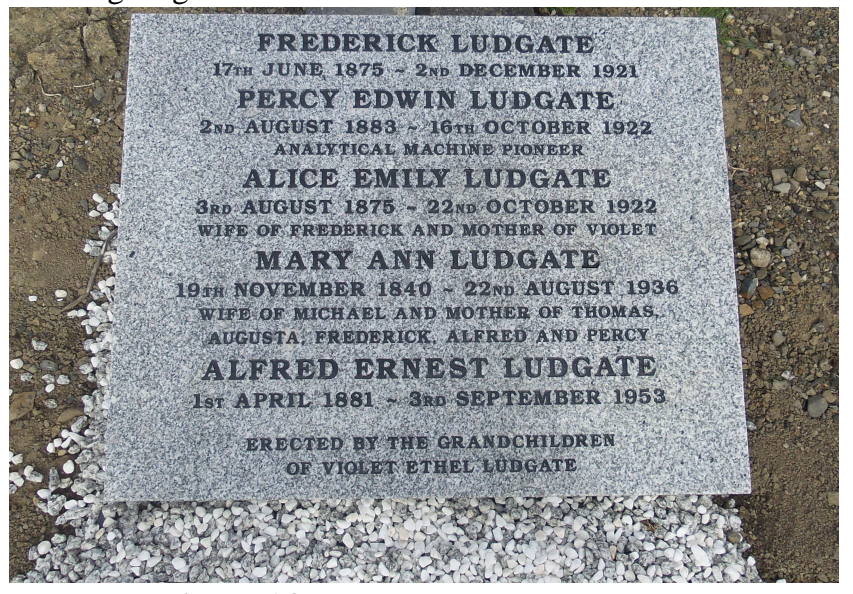

Figure 14 Ludgate grave after Sept. 2019

Images reproduced courtesy The John Gabriel Byrne Computer Science Collection

\section{IV.7. Unknowns about Ludgate's life}

As details of his life are so scant, as of July 2020 there remain, despite our efforts, endless unknowns, for a sample see Table 5.

\begin{tabular}{|l|l|}
\hline Was he at North Strand National School? & Do Percy Ludgate's tax records exist? \\
\hline Did he attend secondary school, and if so, where? & Do Prof. A.W.Conway's papers exist? \\
\hline Which Corn Merchant did he join, and when? & Was he in poor health when he contracted pneumonia? \\
\hline When did he start accountancy? & What ill health caused rejection by the Civil Service? \\
\hline When did he join Kevans \& Son? & Was there a relationship with Timothy Harrington MP? \\
\hline Where is evidence of praise for his WW1 efforts? & Does his civil service file still exist in the UK? \\
\hline Where are his extended relatives and acquaintances? & Do any family letters/photos/documents exist? \\
\hline
\end{tabular}

Table 5 Some known unknowns of Percy Ludgate's life 


\section{V.CONCLUDING REMARKS}

Since Randell's 1971 paper on Ludgate numerous accounts of the history of computing have included coverage of Ludgate's work, but no new material has been published. The new material in the present paper and considerable further material [8][9] has all been found since 2016, the majority since Jan. 2017. By 2019 intensive genealogical efforts had identified his close family and their children, and his ancestors back to the early $18^{\text {th }}$ century. His own life and early career, his close family members, domestic situation, legal issues, and 1909 paper submission, had all been explored but many issues remained outstanding, see [24]. In 2016 the Ludgate Hub was opened where Ludgate was born in Skibbereen [56]. With their help, in 2019 newspaper articles on Ludgate were published in The Southern Star [57] and Cork Examiner newspapers [58]. Subsequently an exploration into his life was presented to the Aug. 2019 West Cork History Festival in Skibbereen [59], and a public call for information was jointly announced by Trinity College Dublin and the Ludgate Hub. This led to our being contacted by Ralf Buelow at Christmas 2019, see below, plus a trickle of other responses. There is further aggregated information in the online catalog at [8], but clearly there are still many known unknowns relating to both Percy Ludgate's life and his work.

Our research has led to two significant discoveries, firstly at Christmas 2018 of the existence of Violet Ludgate's daughter and descendants, secondly at Christmas 2019 the discoveries of the articles and especially the diagram in "The English Mechanic", then the discovery of the original of this material in "Engineering", transcribed here as Appendix I. These led to further works, which are still in progress, firstly genealogical investigations (enabling the marking of the Ludgate grave) [60], and secondly efforts to deduce hidden details of Ludgate's analytical machine (the subject of Section III.3 above regarding Ludgate's logarithmic multiplier, and more generally and extensively of [9]).

\section{ACKNOWLEDGMENTS}

The authors would like to thank Gerry Kelly (a pseudonymous contributor of detail on Ludgate's previously unknown civil service career), Prof. John Tucker, Univ.College Swansea, UK (for access to the Riches thesis on Ludgate [61]), Canon Eithne Lynch, Mallow Church of Ireland (who has been very generous with her time looking up records), Dr. Susan Hood, RCB Library, Dublin (for help in accessing records), Royal Dublin Society Library (for access to records), Adrienne Harrington (Ludgate Hub), Victoria and Simon Kingston (West Cork History Festival), Lorcan Clancy (for audio and video recordings), and the Irish Government (for its generosity in establishing and populating their genealogy website http://www.irishgenealogy.ie/ with Irish civil and church records), the Gonzalez family (for their support), Ralf Buelow of Heinz Nixdorf MuseumsForum and Eric Hutton (for discovery of the articles in "The English Mechanic"), Jade Ward of the University of Leeds Library (for discovery of the article reproduced in Appendix I), and Eric Hutton, Jade Ward, and The Southern Star (for permission to publish the images). Finally our thanks for the support of the School of Computer Science and Statistics, Trinity College Dublin, for this work and for The John Gabriel Byrne Computer Science Collection [7].

\section{APPENDIX I \\ From: ENGINEERING, $20^{\mathrm{TH}}$ AUG. 1909, PAGES 256-257 [21] \\ OPTICAL CHARACTER RECOGNITION COURTESY DAVID MCQUILLAN A PROPOSED ANALYTICAL MACHINE}

By name, at any rate, Babbage's famous analytical engine is known to all. It was intended to be a machine for the arithmetical solution of all problems in mathematical physics. Such solutions are generally, perhaps always, feasible, but in most cases when the computations have to be effected by direct human agency, they are so extremely tedious as to be practically, if not theoretically, impossible. Every operation in arithmetic can be reduced to addition, subtraction, multiplication, and division, and, indeed, the two latter operations can be regarded as mere extensions of the two former. The analytical engine was a machine by which these four operations could be performed in any desired sequence ; moreover, a number of partial operations could be combined, and the final results automatically tabulated for any required values of the variable. As is well known, though many years' labour was spent on the machine, it was never even partially completed, Mr. Babbage's scheme being far too ambitious for a first effort. He wished, indeed, to tabulate values to 50 significant figures, thus enormously complicating the mechanism and augmenting the cost of the experiment. In a paper read not long ago before the Royal Dublin Society, Mr. Percy E. Ludgate has revived again the idea of constructing such a machine: As proposed by him, the machine differs from that of Babbage in some fundamental details, though, as in its predecessor, Jacquard cards will be used to control the sequence of operations. Thus if, for instance, a number of values of the series

$$
y=x-\frac{x^{2}}{2^{2}}+\frac{x^{3}}{2^{2} \cdot 3^{2}}-\frac{x^{4}}{2^{2} \cdot 3^{2} \cdot 4^{2}}+\& c .
$$


were required, the appropriate card would be placed in the machine, which would then, for different values of $x$, calculate each term of the series, add all the positive terms together, subtract from this sum all the negative, and print the result. For a different series a different card would be used.

In Babbage's engine it was proposed to effect multiplication by successive additions, and divisions by successive subtractions, just as is now done in the case of the ordinary arithmometer. Mr. Ludgate, in his engine, proposes to effect these operations on entirely different principles. Multiplication is effected by a series of index numbers analogous to logarithms;

The arrangement is shown diagrammatically in Fig. 1 [see Figure 15]. Here the number 813,200 is to be multiplied by 9247. The arrow under 8 represents a slide, which to denote 8 is set at $\frac{3}{8}$ above the zero or starting line. The slide representing 1 lies on the starting line, whilst that representing 3 stands $\frac{7}{8}$ in. above this line, and that corresponding to the number two $\frac{1}{8}$ in. above. On the other hand, the slides representing zero are set 50 eighths above the. starting line. The number of units above the starting line corresponding to each digit of the multiplicand are known as index numbers, and a complete table of these has been drawn up by Mr. Ludgate. All the slides aforementioned are mounted in a frame, and to multiply by. 9, this frame is moved up over another frame divided with another series of index numbers. Thus, as shown, the distance between the lower frame and the starting line is such that the top of this lower frame lies on the index number corresponding to 9; that is, 14 eighths below the starting line. The lower end of the No. 8 slide, represented by the black circle, rests then, it will be seen, on a line marked "72," which is "the product of 8 and 9. The digits 7 and 2 appear accordingly on the register below. Similarly; the tail of the No. 1 slide rests on the No. 9 line, that of the No: 3 slide on the No. 27 line, and that of the No. 2 slide on 18 , corresponding to the partial products $9 \times 1$; $9 \times 3$; and $9 \times 2$. The tails of the zero slides rest on no line in the lower frame, and hence zero is registered for these. All these partial products are registered in the mill below, as indicated. In a final operation these partial products are added together as indicated, giving 7,318,800. If now the frame is moved to the index number below the starting line marked "2," it will be found, on trial with a piece of tracing paper, that the tail of the No. 8 slide rests now on the line marked "16" - i.e., $8 \times 2$. That of the No. 1 slide on the index-line marked "2," that of slide 3 on the line marked "15," and that of the No. 2 slide on the line marked "10." These partial products will then appear on the mill and be added together, giving the result of the multiplication of 813,200 by 2 . The process is repeated for the remaining figures of the multiplier, and the whole added together so as to give the product of $813,200 \times 9247$. Mr. Ludgate proposes to give such products to twenty significant figures, the time required being, he states, about 10 seconds.

To divide one number by another he proceeds in a different fashion. He notes that the expression $\frac{p}{q}$, where $p$ and $q$ are any two numbers, can always be expressed in the form-

$$
\frac{p}{q}=\frac{\mathrm{A} p}{1+x}
$$

where $x$ is a small quantity, and $\mathrm{A}$ is the reciprocal of some number between 100 and 999.

The above expression can also obviously be written

$$
\frac{p}{q}=\mathrm{A} p\left(1-x+x^{2}-x^{3}+x^{4}-x^{5},+\& c .\right),
$$

the series being very rapidly convergent, the first eleven terms give the value of $\frac{1}{1+x}$ correct to at least twenty figures.

He proposes to perform division, therefore, by making the machine first calculate the value of this series, after which it will multiply A $p$ by the value thus found. As a maximum, he considers that this operation, giving the result correct to twenty figures, might require $1 \frac{1}{2}$ minutes. 


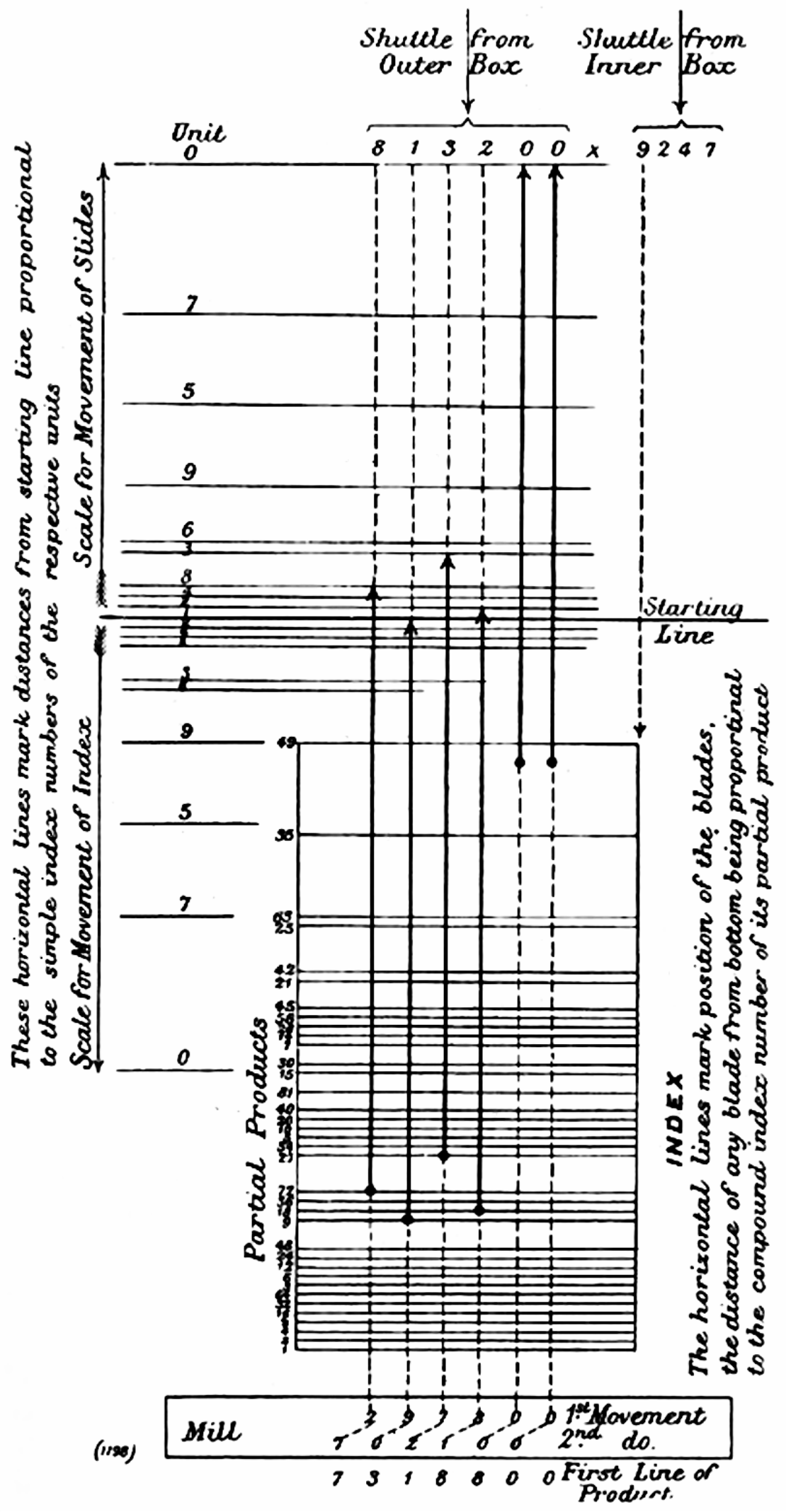

Figure 15 Diagram from “Engineering”, Aug. 20, 1909, Pages 256-257 [21]

Image reproduced courtesy Jade Ward of University of Leeds Library 


\section{REFERENCES,}

[1] P. Ludgate, On a proposed analytical machine, Scientific Proceedings of the Royal Dublin Society, Vol.12, No.9, pp.77-91, 28-Apr-1909. Also reproduced in [5].

[2] C. Boys, A new analytical engine, Nature, Vol.81, pp.14-15, Jul-1909. Also reproduced in [5].

[3] A. Lovelace, Sketch of the Analytical Engine invented by Charles Babbage, Esq. By L.F. Menabrea, of Turin, Officer of the Military Engineers, with notes by the Translator, Scientific Memoirs, Ed.R.Taylor, Vol.3, pp.666-731, 1843. Available at: https://www.scss.tcd.ie/SCSSTreasuresCatalog/literature/TCD-SCSS-V.20121208.870/TCD-SCSS-V.20121208.870.pdf

[4] B. Collier, Little Engines That Could've: The Calculating Machines of Charles Babbage, Ph.D. Thesis, Harvard University, 1970. Available at: http://robroy.dyndns.info/collier/ Also available at [62] in file: "TheLittleEnginesThatCouldve-TheCalculatingMachinesOfCharlesBabbage.pdf".

[5] B. Randell, Ludgate's analytical machine of 1909, The Computer Journal, Vol.14, No.3, pp.317-326, IEEE, 1971. Available at [62] in file: "Randell-Ludgates-Analytical-Machine-of-1909-TheComputerJournal-1971-317-326.pdf".

[6] B. Randell, From analytical engine to electronic digital computer: The contributions of Ludgate, Torres, and Bush, Annals of the History of Computing, Vol.4, No.4, IEEE, Oct. 1982. Available at [62] in file:

"Randell-Contributions-of-Ludgate-Torres-and-Bush-IEEEAnnals-1982-4-4.pdf".

[7] Trinity College Dublin, The John Gabriel Byrne Computer Science Collection. Available at: https://www.scss.tcd.ie/SCSSTreasuresCatalog/

[8] Trinity College Dublin, Percy E. Ludgate Prize in Computer Science. Available at: https://www.scss.tcd.ie/SCSSTreasuresCatalog/miscellany/TCD-SCSS-X.20121208.002/TCD-SCSS-X.20121208.002.pdf

[9] B. Coghlan, Percy Ludgate's Analytical Machine, Trinity College Dublin. Available at [62] in file: "BrianCoghlan-PercyLudgatesAnalyticalMachine.pdf".

[10] Royal Dublin Society, Minutes of the RDS Scientific Committee for 1908-1909, RDS Library, Dublin.

[11] B. Coghlan, Brian, personal communications with grandson of Prof. C.V.Boys, 2017-18.

[12] Irish Newspaper Archives, Communications, p.6, Freemans Journal, $23^{\text {rd }}$ Feb. 1909, Also Irish Newspaper Archives, R.D.Society Scientific Meeting, p.6, Irish Independent, $24^{\text {th }}$ Feb. 1909.

[13] Fujitsu, FUJITSU Supercomputer PRIMEHPC FX1000: An HPC System Opening Up an AI and Exascale Era, Available at: https://www.fujitsu.com/downloads/SUPER/primehpc-fx1000-hard-en.pdf Also available at [62] in file: "Fujitsu-primehpc-fx1000-hard-en.pdf".

[14] G. Saudan, Swiss calculating machines, H. W. Egli A.-G. - A success story, 147 pages, self-published, Yens sur Morges, 2017.

[15] W. MacDonald, John Napier, Dictionary of National Biography, Volume 40, 1885-1900.

[16] P. Hopp, Slide Rules: Their History, Models and Makers, ISBN 1879335867, Astragal Press, 1999.

[17] E. Hutton. Available at: http://www.englishmechanic.com Also donation by Eric Hutton of digitized archives of The English Mechanic and World of Science. Available at: https://www.scss.tcd.ie/SCSSTreasuresCatalog/literature/TCD-SCSS-V.20200520.001/TCD-SCSS-V.20200520.001.pdf

[18] R. Buelow, Percy Ludgate, der unbekannte computerpionier \{Percy Ludgate, the unknown computer pioneer\}, Heinz Nixdorf MuseumsForum, 17-Jan2020. Available in German at: https://blog.hnf.de/percy-ludgate-der-unbekannte-computerpionier/ Also Google translation to English, courtesy Brian Randell. Available at [62] in file: "RalfBuelow-HNF-Blog20200117-translation-BRandell-v2-20200117-0756.pdf".

[19] Scientific News: No. 9 of the Scientific Proceedings of the Royal Dublin Society, English Mechanic and World of Science, No. 2302, p. 322, 7-May-1909, discovered by Ralf Buelow, and image provided by Eric Hutton 19-Dec-2019. Available at [9], and also available at [62] in file: "THE-ENGINEER-image15657-RalfBuelow-EricHutton-20191220-0329.jpg".

[20] Engineering (attribution): A proposed analytical machine, English Mechanic and World of Science, No. 2319, p. 111, Vol. 90 (1909/10), 3-Sep-1909, discovered by Ralf Buelow, and image provided by Eric Hutton 19-Dec-2019. Available at [9], and also available at [62] in file: "THE-ENGINEER-image14800-RalfBuelow-EricHutton-20191220-0329.jpg".

[21] A proposed analytical machine, Engineering, pp.256-257, 20-Aug-1909, discovered by Jade Ward, Univ.Leeds Library, 14-Jan-2020, OCR by David McQuillan, 3-Feb-2020, and image provided by Jade Ward 14-Jan-2020. Available at [9], and also available at [62] in file: "ENGINEERING1909-JadeWard-UnivLeedsLib-2020114-1111.pdf".

[22] D. McQuillan, The Feasibility of Ludgate's Analytical Machine. Available at:http://www.fano.co.uk/ludgate/Ludgate.html Also available at [62] in file: "McQuillan-The-Feasibility-of-Ludgates-Analytical-Machine-20160126-0607.pdf".

[23] Trinity College Dublin, Percy E. Ludgate: Part A1, Prize in Computer Science. Available at [62] in file: "TCD-SCSS-X.20121208.002-20191027-1533-Draft-partA1.pdf".

[24] Trinity College Dublin, Percy E. Ludgate: Part A2, Extended Discussion. Available at [62] in file: "TCD-SCSS-X.20121208.002-20191027-1533-Draft-partA2.pdf".

[25] Trinity College Dublin, Percy E. Ludgate: Part B1a, Genealogy Report. Available at [62] in file: "TCD-SCSS-X.20121208.002-20191027-1533-Draft-partB 1 a-PercyLudgate-Report.pdf", and Part B1b, Pedigree. Available at [62] in file: "TCD-SCSS-X.20121208.002-20191027-1533-Draft-partB1b-PercyLudgate-Pedigree-A3.pdf"

[26] Trinity College Dublin, Barbara Hopkins: Part B2a, Genealogy Report. Available at [62] in file: "TCD-SCSS-X.20121208.002-20191027-1533-Draft-partB2a-BarbaraHopkins-Report.pdf", and Part B2b, Pedigree. Available at [62] in file: "TCD-SCSS-X.20121208.002-20191027-1533-Draft-partB2b-BarbaraHopkins-Pedigree-A3.pdf".

[27] Trinity College Dublin, Eileen Mary Ludgate: Part B3a, Genealogy Report. Available at [62] in file: "TCD-SCSS-X.20121208.002-20191027-1533-Draft-partB3a-EileenMaryLudgate-Report.pdf", and Part B3b, Pedigree. Available at [62] in file: "TCD-SCSS-X.20121208.002-20191027-1533-Draft-partB3b-EileenMaryLudgate-Pedigree-A3.pdf".

[28] Trinity College Dublin, Percy E. Ludgate: Part C, Evidence. Available at [62] in file: "TCD-SCSS-X.20121208.002-20191027-1533-Draft-partC.pdf" 
[29] Griffith Valuation, Parish of Kilshannig. Available at: http://www.askaboutireland.ie/griffith-valuation/

[30] Irish Newspaper Archives, M.E.Ludgate, p3, Skibbereen Eagle, $16^{\text {th }}$ Sep. 1882, Also: Irish Newspaper Archives, M.E.Ludgate, p4, Skibbereen Eagle, $18^{\text {th }}$ Nov. 1882.

[31] Dublin Directory 1890-1898, Thoms Directory, Dublin City Library and Archive, Gilbert Library, Pearse Street, Dublin.

[32] G. Kelly, 46 Foster Terrace, attached to personal email to Brian Coghlan, 9-Nov-2019.

[33] 1901 Census Return, 30 Dargle Road, Drumcondra, The National Archives of Ireland.

[34] Hansard, Education (Ireland) Act 1892. Available at: https://api.parliament.uk/historic-hansard/acts/irish-education-act-1892 Also available at: https://en.wikipedia.org/wiki/Raising of school leaving age

[35] London Gazette, pp.3066-3068, 22nd May 1896, pp.3900-3901, 13th July 1897, 14th January 1898, pp.6454-6455, 4th November 1898, p.6029, 19th September 1902, p.7095, 7th November 1902, p.1779, 17th March 1903, pp.5419-5420, 23rd August 1904.

[36] Dublin Directory 1899-1936, Thoms Directory, Dublin City Library and Archive, Gilbert Library, Pearse Street, Dublin.

[37] Weekly Irish Times, London Correspondence, 21st March 1903.

[38] G. Kelly, Percy Edwin Ludgate - Irish Civil Service Saga, attached to personal email to Prof. Brian Randell, 11-Mar-2013.

[39] M. Glusker, Thomas Fowler's Ternary Calculating Machine, The British Society for the History of Mathematics, No.46, 2002. Also in: Journal of the Oughtred Society, 11:2, 2002.

[40] R. Rojas, Konrad Zuse's legacy: The architecture of the Z1 and Z3, Annals of the History of Computing, IEEE, 19(2), pp.5-15, 1997.

[41] Hansard, Vol.141, 20th February 1905. Available at: https://api.parliament.uk/historic-hansard/commons/1905/feb/20/irish-civil-service-case-of-mr-percy

[42] 1911 Census Return, 30 Dargle Road, Drumcondra, The National Archives of Ireland.

[43] P. Ludgate, Automatic Calculating Machines, In: Handbook of the Napier Tercentenary Celebration or modern instruments and methods of calculation, Ed: E.M.Horsburgh, 1914.

[44] B. Coghlan, Speculations on Percy Ludgate's Difference Engine, Trinity College Dublin. Available at [62] in file: "BrianCoghlan-Speculations-on-Percy-Ludgates-Difference-Engine.pdf"

[45] Wikisource, 1911 Encyclopædia Britannica/Calculating Machines. Available at: https://en.wikisource.org/wiki/1911_Encyclop\%C3\%A6dia_Britannica/Calculating_Machines Also available at [62] in file: "Encyclopaedia-Britannica-11thEdition-Vol4Part4-1911-wikisource.pdf".

[46] D. Baxandall, Calculating machines and instruments: Catalogue of the Collection in the Science Museum, Science Museum, London, 1926.

[47] Irish Newspaper Archives, Corporate Accounts Exams, p.4, Irish Independent, $2^{\text {nd }}$ Sep. 1916.

[48] Government of Ireland, Dublin Institute of Technology Act, 1992. Available at: http://www.irishstatutebook.ie/eli/1992/act/15/schedule/1/enacted/en/html Also available at [62] in file: "Dublin-Institute-of-Technology-Act-1992.pdf".

[49] Corporation of Accountants, Corporate Accountants, Results of the June Examination, Freeman's Journal, p.2, 15-Sep-1917.

[50] Obituary, Dan McGing, Sunday Independent, Independent News \& Media PLC, 28-Oct-2012.

[51] M. Roser, Life Expectancy. Available at: https://ourworldindata.org/life-expectancy/ Also available at [62] in file: "Roser-Life-Expectancy-Our-World-in-Data-withIreland-20200929-1908.pdf".

[52] G. McConnell, A Manual Of Pathology, W.B.Saunders, 1915.

[53] K. Zürcher, M. Zwahlen, M. Ballif, H. Rieder, M. Egger, and L. Fenner, Influenza pandemics and Tuberculosis mortality in 1889 and 1918: Analysis of historical data from Switzerland, PLOS, 5-Oct-2016.

[54] Mount Jerome Cemetery. Available at: http://www.mountjerome.ie/

[55] P. Ludgate, NAI/CS/PO/TR Will of Percy Edwin Ludgate, $26^{\text {th }}$ June 1917, National Archives of Ireland.

[56] N. Baker, Potential €37m impact of digital life on Skibbereen, Irish Examiner, p.7, 5-Nov-2015.

[57] D. Forsythe, Could WW1 have ended Ludgate's computer dreams?, The Southern Star, 27 July 2019.

[58] K. O'Neill, West Cork's Own Computer Pioneer, Cork Examiner, $6^{\text {th }}$ August 2019.

[59] B. Coghlan, An exploration of the life of Percy Ludgate, West Cork History Festival, Skibbereen, 10 ${ }^{\text {th }}$ August 2019. Available at [62] in file: "BrianCoghlan-An-exploration-of-the-life-of-Percy-Ludgate-wAnim.pdf".

[60] B. Coghlan, B. Randell, P. Hockie, T. Gonzalez, D. McQuillan, R. O’Regan, "Percy Ludgate (1883-1922), Ireland's first computer designer: His family, life and work", manuscript in preparation, 2020.

[61] D. Riches, An Analysis of Ludgate's Machine Leading to the Design of a Digital Logarithmic Multiplier, Dept.Electrical and Electronic Engineering, University College, Swansea, June 1973. Available at [62] in file:

"Riches-An-Analysis-of-Ludgates-Machine-UniversityCollegeSwansea-fromBrianRandell-20170203-1352.pdf"

[62] Trinity College Dublin, Percy E. Ludgate folder. Available at: https://www.scss.tcd.ie/SCSSTreasuresCatalog/miscellany/TCD-SCSS-X.20121208.002/ 